\title{
Study on the Governance Path of Civil Aviation Rights Protection in Illegal Way
}

\author{
Linli Yao \\ Guangzhou Civil Aviation College, Guangzhou 510403, China \\ 13067380@qq.com
}

Keywords: Civil Aviation Rights Protection in Illegal Way, Governance Problem, Governance Path.

\begin{abstract}
On the basis of the definition of the characteristics, the elements and the forms of the civil aviation rights protection in illegal way, dissect the defects in the legal regulation and industry management of the civil aviation rights protection in illegal way. This paper probes into the path of building multi-dimensional governance of civil aviation rights protection in illegal way: the improvement of the legal regulation of civil aviation rights protection in illegal way; joint early warning system construction of civil aviation rights protection in illegal way; joint governance mechanism innovation of civil aviation rights protection in illegal way; strengthen the propaganda and education of civil aviation rights protection in illegal way.
\end{abstract}

\section{Introduction}

With the rapid development of civil aviation transport industry, air transport has become a very popular way of travel. At the same time, air transport related links inevitably generate some delays due to the delay in performance of the carrier's air transportation contracts, resulting in the increasing number of conflicts between passengers and airlines, airports, and so on. Such as beating civil aviation personnel, destroying airport facilities and equipment, attacking runways, intercepting aircraft and spreading false and horror information, passengers often propagate to safeguard their legitimate rights and interests. Such acts have endangered the safety of aviation and disrupted the order of air transport, and it is imperative for our country to effectively govern such behavior. It is of positive practical value and positive significance to explore the governance path of civil aviation rights protection in illegal way.

\section{The definition of civil aviation rights protection in illegal way}

\subsection{The definition of civil aviation rights protection in illegal way}

Safeguarding rights means safeguarding the legitimate rights and interests of individuals or groups. The premise of safeguarding rights is the existence of rights. In practice, the rights declared by the rights holders are roughly three kinds of forms, such as legal rights, customary rights and moral rights. Legal rights protection should be based on legal rights and take legal means to realize the protection of legal rights or rights and interests through legal means. Illegal rights protection is a way to maintain illegal rights and interests when it is infringed on rights or interests. It lacks procedural legitimacy, and it is a product of improper private remedy. Most of the manifestations are parties' illegal behaviors such as illegal gathering, violence, smashing, blocking and blocking roads, and coercive units and departments to achieve their own interests.

The civil aviation rights protection in illegal way is an illegal act of safeguarding rights in the field of civil aviation, that is, the participants of civil air transport activities, when their legitimate rights or interests are infringed; they take an illegal way of safeguarding their rights. When it comes to the transport contract claims not to perform, delay in performance, personal rights and property rights infringement violations, especially in flight delays in the disputes of passengers due to enhanced awareness of rights, and express their demands and seek compensation of the urgency, but the lack of legal awareness of their own rights behavior, often abandon the contract change and complaints, 
judicial relief and other legal means, but take the opposite with the airlines, airports, public security organs, illegal way endanger aviation safety, disrupt the order of the airline for rights.

\subsection{The classification of civil aviation rights protection in illegal way}

According to the consequences, civil aviation rights protection in illegal way can be divided into two categories: civil aviation rights protection in illegal way that threaten flight safety and civil aviation rights protection in illegal way that disrupt the order of air transportation. Civil aviation rights protection in illegal way that threaten flight safety are aircraft hijacking, explosion in aircraft, attempted to enter the aircraft cockpit without permission, beating the crew members or threatening to harm others, hinder the crew members to perform their duties, false danger endanger flight safety, theft or vandalism life-saving equipment, illegal open machine emergency equipment (emergency door forced open).Civil aviation rights protection in illegal way that disrupt the order of air transportation are disturb, beating passengers, destruction of public facilities (violence smashed counters), the impact of the airport (Flushing the apron, Intercepting aircraft),seizure of aircraft etc. According to the different places, civil aviation rights protection in illegal way can be divided into illegal activities on aircraft and illegal rights in the airport.

\subsection{The characteristics of civil aviation rights protection in illegal way}

One is that the civil aviation rights protection in illegal way has certain rationality. The civil aviation rights protection in illegal way is due to the improper or untimely handling of flight delay disputes, which leads to the excessive and illegal maintenance of the rights and interests of the passengers. If appeal to the cause, it is still reasonable. The two is the coexistence of sudden and predictability. The weather causes, such as the cause of flight delays are threatened, can be pre judged. Therefore, the civil aviation passengers' illegal rights protection behavior caused by the flight delay dispute has the characteristics of sudden and foreseeable coexistence. Three is the coexistence of civil aviation rights protection in illegal way of individuals and groups. Because of the passenger conflict caused by flight delays, its own group characteristics are prominent. Illegal rights protection activities are easy to expand from a single person, such as a troublemaker, to their groups, and thus evolve into collective rights protection. The four is the coexistence of conflict and harmfulness. Because of the different degree of conflict, it can be divided into general and serious conflicts. In terms of harmfulness, one will disturb the normal aviation operation order; two, it will endanger the aviation safety; three, it is a serious consequence that disrupts public order, causes personnel injury, and damages public and private property.

\section{Problems existing in the management of civil aviation rights protection in illegal way}

\subsection{The defects in the legal regulation of civil aviation rights protection in illegal way}

Under the current environment of civil aviation in China, laws and regulations have defects and limitations in the regulation of civil aviation rights protection in illegal way, and the cost of illegal rights protection is low.

First, the laws and regulations have not clearly defined civil aviation rights protection in illegal way. In the aspect of law, civil aviation rights protection in illegal way is not defined as a separate crime or illegal acts in "Civil Aviation Law". Only a general provision is made to the actions and penalties that threaten aviation security and disrupt the order of the air. In the aspect of laws and regulations, "Civil Aviation Security Ordinance" is the only one system general provisions of illegal acts against the order of the airline and aviation safety special administrative regulations in China, there is no direct provisions on the civil aviation rights protection in illegal way. The prohibition in the aircraft and the airport is stipulated only in the way of generalizations and enumerates. As "Civil Aviation Security Ordinance" is administrative regulation, it does not have the right to deprive the right of personal liberty, and the regulation does not provide penalties for such acts. There is no direct regulation on the civil aviation's illegal rights protection behavior in the "public security passenger transport flight safety work rules". Only the illegal interference behavior and disruptive behavior are defined. 7 kinds of illegal interference behavior and 9 kinds of aircraft disturbance are listed.

Secondly, the existing laws and regulations of civil aviation cannot be used as the basis for the law enforcement of the public security organs. "Civil Aviation Law", "Civil Aviation Security Ordinance" 
and other civil aviation laws and regulations do not directly impose penalties for regulating all kinds of crimes or illegal activities. It is generally necessary to invoke the penal code or "Law on Punishment of Public Security Administration".

Thirdly, the "Law on Punishment of Public Security Administration" has limitations in the regulation of civil aviation illegality. The regulations in "Civil Aviation Security Ordinance" and the rules of security for public air passenger transport cannot be fully connected with the regulations regulated by the "Law on Punishment of Public Security Administration". The regulations about disturbing the order of the airport and disrupting the order of general provisions of the aircraft by "Law on Punishment of Public Security Administration" are too general. It does not make a list of behavior and is not operable. Its definition of good order is not clear. It is easy to cause different regions and different law enforcement officers to interpret and apply differently, resulting in the disunity of the application of law.

In addition, the laws and regulations are too weak to punish such acts. Due to the higher requirements of the "criminal law" to constitute a crime, the illegal behavior of civil aviation which has been sanctioned by law in practice is mainly a general illegal act. At present, the punishment for such behavior is too mild. The punishment of the "Law on Punishment of Public Security Administration" is mainly a warning, a fine, or an administrative detention. The maximum penalty is only $5000 \mathrm{RMB}$, administrative detention is the most severe punishment in the category of public security management punishment, and the execution of administrative detention is not more than 20 days. The civil aviation safety regulations impose different penalties for some illegal activities, such as fines, confiscation or seizure of illegally carried articles, but the maximum penalty is only 5000 RMB.

\subsection{The defects in industry management of civil aviation rights protection in illegal way}

The internal standards of the airlines are not uniform. The service standards of the airlines are not uniform. For the handling of flight delays, there are differences in the standard of compensation and other aspects, which will lead to the psychological drop after the contrast of the passengers, thus triggering the excitement. There are differences in the technology and management processes of the airlines. Airlines have significant differences in internal decision-making, information release, information communication with the airport and other related units, and the technology of the captain. For example, some airlines decision-making process is complicated, the feedback to the headquarters of a long time; some airlines information release lag, or there is no time to explain the real situation of the airport; different airline captain technical differences, and in the same weather conditions, some pilot can fly and some pilot cannot fly, causing passengers feel bad.

There is a difference in the degree of attention to passenger complaints. There are differences and deficiencies in the degree and process of handling passengers' complaints. In the face of passenger complaints, there is no airline to take the initiative to compensate, which is the more compensation the passengers have to make, the more compensation. There are differences in the authority and level of the specialized agencies dealing with complaints of passengers. For example, the authority of the airport complaint center is insufficient and the level is not enough. It is only equivalent to the aftersale Department of the enterprise, which makes the dispute handling not timely and effective.

The efforts to deal with civil aviation rights protection in illegal way are limited. In the face of civil aviation rights protection in illegal way, because the airport screeners, airlines and other security officers do not have law enforcement powers, in the face of civil aviation rights protection in illegal way in airport and aircraft, the security inspector and the security officer have no right to solve the problem immediately. They can only send the alarm to the airport public security or air police, but there are still some problems in the connection of airport security, land service, airlines and public security. However, in the high incidence of civil aviation rights protection in illegal way, especially in mass unexpected incidents caused by large area flight delays, there is a lack of airport police force, which results in limited efforts. 


\section{Construction of the path of multi-dimensional governance of civil aviation rights protection in illegal way}

\subsection{Improvement of the legal regulation of civil aviation rights protection in illegal way}

First of all, according to the situation of imperfection of China's laws and regulations in the field of civil aviation and light punishment to endanger aviation safety and disrupt the order of the air transport behavior, the legislative department and the civil aviation authorities should learn foreign advanced experience in legislation and practice, as well as the International Convention on the basis of domestic law, perfecting and revising the relevant provisions of the civil aviation legal system, formulate relevant laws and regulations, build a favorable mechanism and legal system of civil aviation rights protection in illegal way.

For example, in amendment of "Civil Aviation Law" and "Civil Aviation Security Ordinance", we should increase civil aviation rights protection in illegal way and its punishment measures, or establishing a separate regulation of civil aviation rights protection in illegal way, and providing more specific provisions in "public security passenger transport flight safety work rules" and other departmental rules. In terms of the content of regulation, one is to clear the definition of civil aviation rights protection in illegal way, stating the manifestations of such acts and standards; two is to clearly define the rights of the captain, airport security standards, flight safety regulations, airport security standards, flight delays, the standard of ticket refund and change; three is to make clear the punishment measures for all kinds of civil aviation rights protection in illegal way.

Second, the relevant legal provisions should also be revised and perfected in view of the relevant factors arising from the civil aviation rights protection in illegal way. For the connection between civil aviation laws and regulations and "Law on Punishment of Public Security Administration", we can modify "except for special provisions of law" in the "Law on Punishment of Public Security Administration" to "except for special provisions of laws and administrative regulations". Or make judicial interpretations on the application of "Law on Punishment of Public Security Administration", and incorporate the regulations of civil aviation rights protection in illegal way in civil aviation regulations and regulations into "Law on Punishment of Public Security Administration". In view of the problem of light punishment, first, it is suggested that "Law on Punishment of Public Security Administration" should be revised and the punishment will be strengthened. The special provisions concerning such acts in the civil aviation laws and regulations can be applied according to the revised provisions of "except for special provisions of laws and administrative regulations" of "Law on Punishment of Public Security Administration". For example, by increasing the amount of fines and so on, the punishment of the laws and regulations of the industry will be increased. There is no uniform provision for the compensation standards for flight delays due to civil aviation laws and regulations, which leads to the problem of the inconsistent standards of the various airlines. It is suggested that the unified compensation standard should be perfected in the revision of the regulations on the normal management of flights, in order to eliminate such factors on the basis of law.

Third, it should play the role of industry credit management in the innovation of legal regulation of civil aviation rights protection in illegal way. Based on the practices and experiences of the United States, Canada and other countries, we need to establish a "black list" system for the Civil Aviation Administration in line with the actual needs of China's civil aviation development, and promote the legislation of the "black list" system for civil aviation passengers. Through this system, the dishonesty in the industry caused by civil aviation rights protection in illegal way will be punished. In the specific design of the system, the system should have the right to make the subject legitimacy, making clear the "blacklist" system entry and exit criteria. At the same time, because the system involves basic rights such as citizen's right of personality and freedom of travel, and the group that may be regulated is relatively extensive. The system itself should follow the principles of due process and protection of human rights, and establish rights guarantee mechanism that is compatible with the system.

In addition, at the level of implementation of the law, we should focus on strengthening the industry regulatory functions of civil aviation authorities, giving full play to the supervision function of the civil aviation self regulatory organization (Civil Aviation Industry Association), and effectively 
protecting the rights and functions of civil organizations of civil aviation consumers' rights and interests protection.

\subsection{Building a joint early warning system of civil aviation rights protection in illegal way}

The civil aviation rights protection in illegal way has certain characteristics of potential, reproducibility and predictability. System theory regards people, things and environment as a whole, studies the interaction, feedback and adjustment between people, objects and environment, finds out the reasons, and reveals the way to prevent it. The civil aviation rights protection in illegal way in civil aviation activities, involving in civil aviation activities of the people (passengers, civil aviation personnel, police, etc.) aircraft (in a safe or unsafe condition), transportation conditions (weather, air traffic control and other factors), the parties concerned are airlines, airports, air traffic control department of the public security organs, etc.. The above parties can predict and judge such events according to the flight delay, the handling capacity of the events, and the national legal provisions.

It can be seen that according to system theory, we can build multiple joint early warning system, such as airlines, airports, ATC departments, public security organs, civil aviation authorities, civil aviation industry associations and so on, to establish six party linkage mechanisms. The construction of multi-party linkage early warning system should adhere to the principles of system theory. Under the guidance of system theory, taking into account the theory of passenger service psychology, we will set up an early warning system for civil aviation rights protection in illegal way events through joint warning of endogenous police sources and exogenous police sources.

The most important early-warning management system in the civil aviation rights protection in illegal way event system is the early warning management system. This early warning management system can be all civil aviation, and regional early warning management system can also be established in each area. Early warning management system of civil aviation is dominated by the civil aviation authorities, the forewarning management system of the area is dominated by the regional management departments, airlines, airports, air traffic control departments, public security organs shall be responsible for collecting and reporting the abnormal information, the civil aviation industry association is responsible for tracking such information. In the focus of attention, we need to focus on the national hub airports, airlines and airlines that have more civil aviation rights protection in illegal way. In addition, all parties in the joint early warning system should achieve rapid and effective exchange of effective and accurate information.

\subsection{Innovation of joint governance mechanism of civil aviation rights protection in illegal way}

Based on the establishment of the six party linkage mechanism and the establishment of the multiparty joint early warning system, such as airlines, airports, air traffic control departments, public security organs, civil aviation authorities and civil aviation industry associations, we should innovate the establishment of a joint governance mechanism of civil aviation rights protection in illegal way. The joint governance mechanism includes the contingency plan linkage mechanism of airlines, airports and air traffic control departments, and the Joint Disciplinary Mechanism of public security organs, civil aviation authorities, civil aviation industry associations and airlines. In the current model, when the flight delays, airlines, airports and air traffic control departments will start emergency plans of their own, because of the lack of communication and coordination, it often forms a state of "based on me", and their respective responsibilities and functions are not clear in the response of the emergency plan. The emergency plan linkage mechanism of the airlines, airports and air traffic management departments will cooperate with the tasks and responsibilities of the three parties on the overall strategic level. Especially in the event of mass illegal rights protection caused by large flight delays, airlines and airport parties should communicate with each other to ensure that information transmission is timely, accurate and effective, and coordinate and coordinate related matters. For example, the air traffic control department should inform the airlines and airports of the latest information in a timely manner. The airline should make full use of the hardware facilities of the airport and take the initiative to inform passengers of the delays related to flight delays in a variety of ways. The airport should strengthen the dynamic patrolling of the passengers gathering area, and help to deal with the illegal behaviors of passengers who destroy public and private property and interfere with the normal operation order of airports. 
The public security organs, civil aviation authorities, civil aviation industry associations and airlines should establish joint disciplinary mechanisms for the social impact and the relatively bad behavior of civil aviation passengers. For unlawful acts, the public security organs should give corresponding administrative penalties in accordance with the law of the public security management and punishment law. The civil aviation industry association should clearly include such passengers in civil aviation passengers' uncivilized behavior records according to the regulations on the management of civil aviation passengers' uncivilized behavior (Trial Implementation). The civil aviation authority may introduce the administrative "blacklist" system to restrict such passengers. Airlines can also set up their own and airline blacklists to restrict such passengers on their flights. Thus, the joint governance of "one illegal and restricted" for illegal civil aviation passengers is realized.

\subsection{Strengthen the propaganda and education of civil aviation rights protection in illegal way}

In the industry, we should strengthen the implementation of regulations for the regulation of civil aviation illegal rights protection activities, training for handling such incidents, and the dissemination of reasonable cognition of such behaviors. In the aspect of the publicity and implementation of the laws and regulations, the civil aviation authorities should organize the legal training of employees for civil aviation related posts. We should establish the internal learning mechanism of the industry and strengthen the training of the civil aviation practitioners. The handling of such events has rapid, timely and efficient requirements. It is necessary to establish an emergency management system for various departments. The personnel involved in the process need basic emergency knowledge, crisis handling skills, coping ability of emergencies, and psychological knowledge of passenger service. Airlines and airports should strengthen related training for staff, and also include such behaviors in regular or irregular simulation exercises and situational exercises. At the same time, we must set up the idea of true love service in the industry, while we punish the rigid legal rules, we should better serve the source and reduce the bad factors of the civil aviation rights protection in illegal way.

On the other hand, we should do a good job in publicity and education for the public and to do the work of universal law. First, the competent civil aviation authorities and industry associations should adopt a simple and understandable way to take advantage of all kinds of media to inform the civil aviation consumers which excessive rights protection activities are illegal or even criminal acts. Two, when airlines sell air tickets, they should tell passengers what illegal activities are prohibited. What are the legal basis and what kind of illegal consequences will happen? Three, the airport should also promote relevant information to passengers in a significant ways, such as through a large screen or broadcast.

\section{Conclusion}

Under the reality of the escalation of civil aviation rights protection in illegal way, and the adverse consequences that aviation safety has caused or may cause, as well as the disruption of air transport order and other adverse consequences, it is necessary to establish a set of effective governance methods and explore a way of governance that is in line with the national conditions of our country.

This governance path, considering the regulation of laws and regulations, policy system; establishment of airlines, airports, air traffic control departments, public security organs, the civil aviation authority, the Civil Aviation Industry Association and other multi joint early warning system, forming six linkage, establish innovation based on joint governance mechanism of civil aviation illegal behavior of the main parties involved in human rights the implementation of joint discipline; while strengthening the propaganda and education of illegal behavior governance, build multidimensional governance path.

\section{Acknowledgments}

This article is the research result of the project of the civil aviation safety capability fund of Civil Aviation Administration - "research on legal governance of civil aviation rights protection in illegal way". 


\section{References}

[1]. Yuan Faqiang Shi Tianyi. Research on legal regulation of passenger misconduct China aviation. Journal of Beihang University (SOCIAL SCIENCE EDITION), 2016.1

[2]. Zhao Xuan. "Think vian dilemma and legal building the air downtown incident. Journal of Civil Aviation University of Chinese, 2017.1

[3]. Liu Xiaoping Luo fan. The formation mechanism and early warning of passenger mass unexpected events in the situation of flight delay. Soft science, 2013.11

[4]. Shen Zhimin. Evaluation of the criminal law of excessive rights. Legal edition of the Journal of Yunnan University, 2010.1

[5]. Deng Yongsheng. Evaluation of the illegality of excessive rights. Journal of Shanxi Datong University (SOCIAL SCIENCE EDITION), 2016.10

[6]. Primary discussion on the issue of civil aviation passengers' rights protection in illegal way-A correlation analysis based on empirical investigation. Chinese civil aviation, 2017.12

[7]. Yuan Faqiang. From contract to identity: the evolution of the law on the protection of airline passengers' rights and interests. Jiangxi social science, 2015.4 